\title{
To Observe the Runoff Rate of Areca Plantation on Slopeland
}

\author{
Sen-Hsiung HSU ${ }^{*}$ and Chi TANG ${ }^{* *}$ \\ *Meiho Institute of Technology, Pingtung, Taiwan, R.O.C. \\ **Department of Soil and Water Conservation, National Pingtung University of Science and Technology, \\ Pingtung, Taiwan, R.O.C. Corresponding author.
}

\begin{abstract}
Betel nut is a familiar crop in the middle and southern parts of Taiwan's slopeland. Since the population to chew the betel nut was extended, the consumption and profits were increased. Therefore more slopeland was used to plant areca and would get high quality betel nut. Areca plantations bring the society and natural environment very complicated impacts. There was extensive by different cognition of the soil and water conservation, between proprietor and scholar, recognized about planting areca on slopeland. A number of disasters had taken place on slopeland in recent years. It is unknow whether all the disasters were created by betel nut plantation. As no explicit evidence could be confirmed, it's important to understand the hydrological characteristics of betel nut plantation on slopeland. Experimental watershed was located in Shan-Ann village, Shuli county, Nan-Tao Hsien, Taiwan (elevation $=890 \mathrm{~m}$; latitude $=26^{\circ} 25^{\circ} \mathrm{N}$; longitude $=122^{\circ} 81^{\prime} \mathrm{E}$ ). The precipitation and runoff were observed by raingauge and $H$ type channel from June 1997 to July 1998 . The primary result showed that the runoff coefficient was about 0.53 to 0.76 , and mean value was 0.64 .
\end{abstract}

Keywords: Areca plantation, Betel nut, Runoff rate, Slopeland, Watershed

\section{Introduction}

The farmers are interested in betel nut due to its easy cultivation and high benefit, and that is alleged as the "green gold" in Taiwan. The last phase harvest of betel nut is from April to June every year. The condition of sparse quantity would lead to price rise, and then could earn very high profits for merchant. Not only the low temperatures on the slopeland, but also the slow growth make the period of betel nut harvest delayed, and prolong the prosperous period. A cooler and windless valley plantation is suitable for plating areca with high quality betel nut. Regarding the areca plantation, the farmers would prefer the slopeland in succession. The cultivation of areca and consumption process of betel nut might bring the society and natural environment a really complicated impact. The betel nut industry had occupied the ratio of gross proceeds for the agricultural livestocks and products in Taiwan was $0.064 \%$ in 1961 , and the increased tendency from 1981 to 1989 had been up to $3.1 \%$ in 1989 (Huang et al., 1991). The cultivated area is shown as, 500-700 ha (in 1962), 1670 ha (in 1971) and 56581 ha (in 1996). During the 25 years (1971-1996), the area increment had reached more 34 times than that in 1971 (Wu, 1998). Especially, the cultivated area was increased rapidly from 11061 ha (in 1986) to 33487 ha (in 1989) and the averaged rate of increment was 5600 ha per year. The areca has been planted extensively, and is a widespread crop in Taiwan ( $\operatorname{Lin}, 2002$ ). The distribution of areca is found to be planted, 33, 20 and $18 \%$ in the individual proportions of Pingtung, Nantou and Chiayi County, in addition to that of $16 \%$ for both Hualiean and Taitung.

Therefore, the slopeland productivity can be obtained by decreasing the area of plantation (Wu et al., 1995). It's necessary to build an experimental watershed in betel nut orchard, and it could be inquired into the hydrological characteristics of planted areca on slpoeland (Hsu et al., 1998).

\section{Materials and methods}

\subsection{Experimental site}

The experimental site was located in Shan-Ann village, Shuli county, Nan-Tao Hsien, Taiwan (latitude $=26^{\circ} 25^{\prime} \mathrm{N}$; longitude $=122^{\circ} 81^{\prime} \mathrm{E}$ ). The areca watershed encompasses an area of $6764 \mathrm{~m}^{2}$; the average elevation is $890 \mathrm{~m}$ with the slope inclination of about $30^{\circ}$. The plants were 9 years with the mean height of 6-7 m. The soil texture is Clay Loam and within a lot of fragile sandstone and shale.

\subsection{Instrumentation}

Gross rainfall was measured using a tipping-bucket raingauge $(0.5 \mathrm{~mm}$ bucket, OTA.502, Japan) positioned outlet from the watershed, and approximately $0.4 \mathrm{~m}$ from the ground. The depth of runoff was measured using an $\mathrm{H}$ type channel within the pressure stage recorder (see Fig.1), and the rating curve between runoff depth and water stage is shown in Fig. 2. The data were acquired using automatic instruments every 5 minutes, and were stored on a 
data logger (CR10X, Campbell Scientific Instrument, USA).

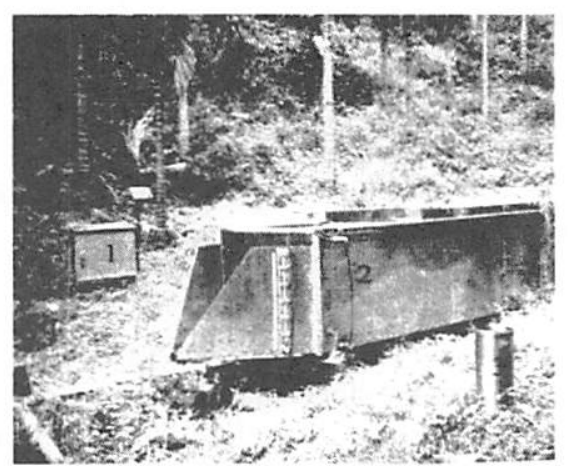

Fig.1 Photography of instrumentation( 1:data logger; $2: H$ type channel; 3 :rainfall gauge)

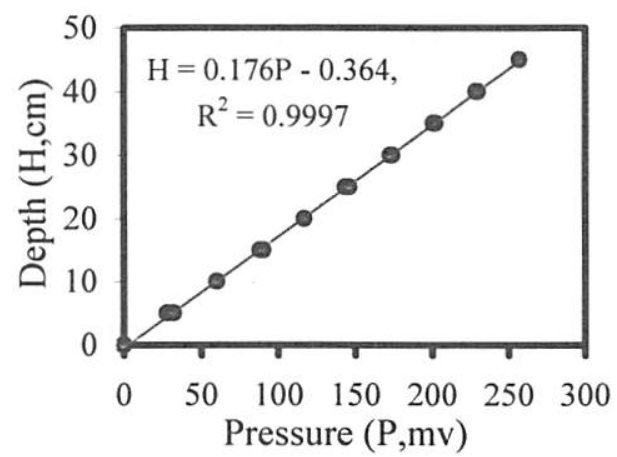

Fig.2 The rating curve of depth and pressure in runoff

\subsection{Hydrograph analysis}

Chen (1983) recommended that Barnes's method could be analyzed by hydrograph analysis in Taiwan, to match the time interval of 5 minutes, which was adopted in this study. The hydrograph can show the variation of runoff at a semi-logarithmic graph paper with logarithm of discharge in the vertical axis and runoff duration in the horizontal axis. From the curve, the threshold of runoff, base discharge and direct discharge can be predicted. Both the discharges were distinguished by connecting the increased point of runoff and the second turning point of recession hydrograph behind peak flow, in which the lower part was the base flow and the upper part was direct runoff.

When rainfall is exceeded infiltration would lead to runoff, and the moment to time of peak flow (Tp) could be used to count the lag time, $\mathrm{T}_{\mathrm{L}}$ (see Fig. 3).

The denser canopy would prolong the time of peak flow and recession, and its contrary was in sparse canopy. The prolonged recession time would make the hydrograph smoother, and decrease the runoff. The variation after rainfall could be predicted by the recession constant (Liang, 1996).

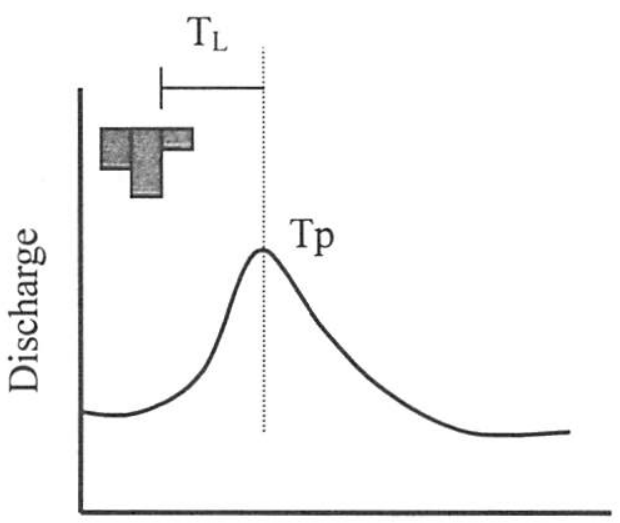

\section{Duration}

Fig. 3 The diagram of lag time $\left(T_{L}\right)$

The recession constant $(\mathrm{Kr})$ is the gradient of recession curve in the hydrograph, and therefore $\mathrm{Kr}$ can be calculated as:

$$
\begin{gathered}
\mathrm{Q}_{1}=\mathrm{Kr} \mathrm{Q}_{0} \\
\mathrm{Q}_{2}=\mathrm{Kr} \mathrm{Q_{1 }}=\mathrm{Kr}^{2} \mathrm{Q}_{0} \\
\mathrm{Q}_{3}=\mathrm{Kr} \mathrm{Q_{2 }}=\mathrm{Kr}^{3} \mathrm{Q}_{0} \\
\cdot \\
\cdot \\
\mathrm{Q}_{\mathrm{t}}=\mathrm{Kr} \mathrm{Q}_{\mathrm{t}-1}=\mathrm{Kr}^{\mathrm{t}} \mathrm{Q}_{0}
\end{gathered}
$$

Where $\mathrm{Q}_{0}$ is the threshold discharge of recession curve, $Q_{1}, Q_{3}, Q_{3}, \cdots Q_{t}$ denote the discharge of recession curve in various periods. Taking the logarithm of both sides of the equation $\mathrm{Q}_{\mathrm{t}}=\mathrm{Kr}^{\mathrm{t}} \mathrm{Q}_{0}$, we obtain

$$
\log \left(\mathrm{Q}_{\mathrm{t}}\right)=\mathrm{t} \cdot \log (\mathrm{Kr})+\log \left(\mathrm{Q}_{0}\right)
$$

Then $\log (\mathrm{Kr})=\left[\log \left(\mathrm{Q}_{\mathrm{t}}\right)-\log \left(\mathrm{Q}_{0}\right)\right] / \mathrm{t}$

Thus, by taking the inverse of the logarithmic equation can provide $\mathrm{Kr}$.

We can also plot $Q_{0}, Q_{1}, Q_{2}, Q_{3}, \cdots Q_{t}$ of hydrograph in the logarithmic graph paper, and $\mathrm{Kr}$ can be diagrammatized by the gradient between $\mathrm{Q}_{\mathrm{t}}$ $\mathrm{Q}_{0}$ and $\mathrm{t}$ (see Figs.4 and 5).

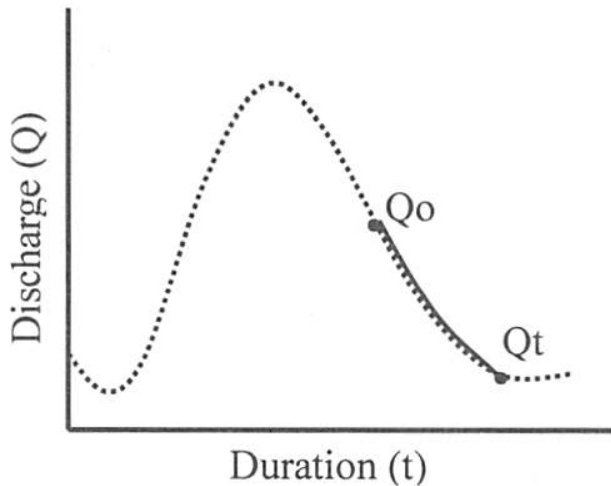

Fig. 4 Recession flow in hydrograph 


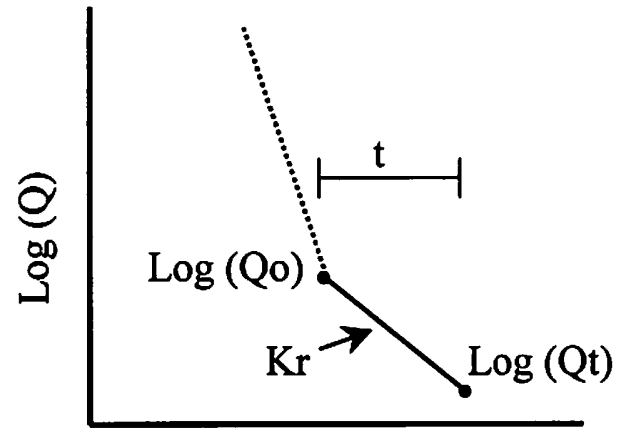

Duration ( $\mathrm{t}$ )

Fig. 5 The logarithmic recession flow in hydrograph

\section{Results and discussion}

\subsection{The gross rainfall of areca watershed}

Since the typhoons appeared during the study period damaged the instrumentations, there were only 12 rain events that could be used to analyze from June 1997 to July 1998. All the individual rainfalls are listed in Table 1.

Table 1 The effective rainfall of areca watershed from June 1997 to July 1998.

\begin{tabular}{ccc}
\hline Date & Duration & Rainfall (mm) \\
\hline 1997.6 .10 & $11: 00 \sim 19: 15$ & 12.5 \\
1997.6 .11 & $12: 20 \sim 14: 50$ & 11.5 \\
1997.6 .12 & $10: 20 \sim 18: 25$ & 11.0 \\
1997.6 .13 & $15: 55 \sim 21: 45$ & 23.5 \\
1997.6 .14 & $03: 45 \sim 17: 30$ & 11.0 \\
1997.6 .15 & $15: 20 \sim 21:: 45$ & 16.0 \\
1997.6 .23 & $18: 50 \sim 21: 15$ & 22.0 \\
1997.6 .26 & $18: 05 \sim 02: 10$ & 52.0 \\
1997.6 .27 & $15: 50 \sim 19: 05$ & 14.5 \\
1997.6 .28 & $17: 30 \sim 21: 10$ & 29.5 \\
1998.7 .01 & $13: 50 \sim 17: 45$ & 15.5 \\
1998.7 .09 & $15: 45 \sim 21: 45$ & 29.5 \\
\hline
\end{tabular}

\subsection{The surface runoff of areca watershed}

Both base-flow separation and effective rainfall were used to analyze the surface runoff. The base-flow separation adopted single-peak hydrograph. The effective rainfall was defined by the individual rainfall which was more than $10 \mathrm{~mm}$ at an interval of six hours. To comprehend the runoff, lag time and recession constant by the individual hydrograph in the observed period, we summarized those results as shown in Tables 2 and 3; where June 11, 1997 and July 9, 1998 are plotted in Figs. 6 and 7.

Since the continuous rainfall from June 11-14, 1997 would gradually decrease the lag time from Table 3, can find June 11 is 23 min but June 14 being reduced to $5 \mathrm{~min}$. A different situation was appeared on June 23,1997 . There were eight days without rainfall before June 23 , and the resulting lag time was 34 minutes. After three days two continuous separate rainfall events were occurred on June 26 and 27, the individual rainfall were found to be 52 and $14.5 \mathrm{~mm}$, and we could know the lag time was apparently reduced to 2 minutes on the second day, i.e., continuous rainfall would decrease the infiltration and shorten the duration of peak flow. The calculated recession constants would be increased with recession time (or rate), and its extent was about 0.27 to 0.47 , with an average value of 0.35 .

Table 2 Hydrological analyses for 12 individual rainfalls in watershed of betel nut orchard

\begin{tabular}{|c|c|c|c|c|}
\hline Date & Duration & $\begin{array}{c}\begin{array}{c}\text { Discharge } \\
\text { (cms) }\end{array} \\
\end{array}$ & $\begin{array}{c}\text { Rainfall } \\
\text { (mm) }\end{array}$ & $\begin{array}{c}\text { Runoff } \\
\text { coef. }\end{array}$ \\
\hline 1997.6 .10 & $11: 00 \sim 19: 15$ & 0.014 & 12.5 & 0.61 \\
\hline 1997.6.11 & $12: 20 \sim 14: 50$ & 0.014 & 11.5 & 0.62 \\
\hline 1997.6 .12 & $10: 20 \sim 18: 25$ & 0.015 & 11.0 & 0.70 \\
\hline 1997.6.13 & $15: 55 \sim 21: 45$ & 0.028 & 23.5 & 0.64 \\
\hline 1997.6 .14 & $03: 45 \sim 17: 30$ & 0.014 & 11.0 & 0.68 \\
\hline 1997.6.15 & $15: 20 \sim 21: 45$ & 0.020 & 16.0 & 0.67 \\
\hline 1997.6.23 & $18: 50 \sim 21: 15$ & 0.025 & 22.0 & 0.60 \\
\hline 1997.6 .26 & $18: 05 \sim 02: 10$ & 0.074 & 52.0 & 0.76 \\
\hline 1997.6.27 & 15:50 19:05 & 0.016 & 14.5 & 0.59 \\
\hline 1997.6.28 & $17: 30 \sim 21: 10$ & 0.037 & 29.5 & 0.67 \\
\hline 1998.7.01 & $13: 50 \sim 17: 45$ & 0.015 & 15.5 & 0.53 \\
\hline 1998.7.09 & $15: 45 \sim 21: 45$ & 0.035 & 29.5 & 0.62 \\
\hline Mean & & 0.025 & 20.6 & 0.64 \\
\hline
\end{tabular}

Table 3 To analyze lag time in watershed of betel nut orchard

\begin{tabular}{ccc}
\hline Date & Duration & $\begin{array}{c}\text { Lag time } \\
\text { (min) }\end{array}$ \\
\hline 1997.6 .11 & $12: 20 \sim 14: 50$ & 23 \\
1997.6 .13 & $15: 55 \sim 21: 45$ & 11 \\
1997.6 .14 & $03: 45 \sim 17: 30$ & 5 \\
1997.6 .23 & $18: 50 \sim 21: 15$ & 34 \\
1997.6 .27 & $15: 50 \sim 19: 05$ & 2 \\
1997.6 .28 & $17: 30 \sim 21: 10$ & 15 \\
1998.7 .01 & $13: 50 \sim 17: 45$ & 60 \\
1998.7 .09 & $15: 45 \sim 21: 45$ & 52 \\
\hline Mean & & 25 \\
\hline
\end{tabular}

\section{Conclusion}

The results from this study indicate that the runoff coefficient occurred was between 0.53 and 0.76 , and mean value was about to 0.64 , which is more than that of normal forest $(0.51)$ in Taiwan. The damage to water resources conservation by planting areca on slopeland has already been reported (Chen, 1999). During the observed periods, the recession constants obtained were about 0.27 to 0.47 , which are smaller than that of forest $(0.95$ to 0.99$)$. As remarked, while recession time is shorter, the effect of water resources conservation would be decreased. 


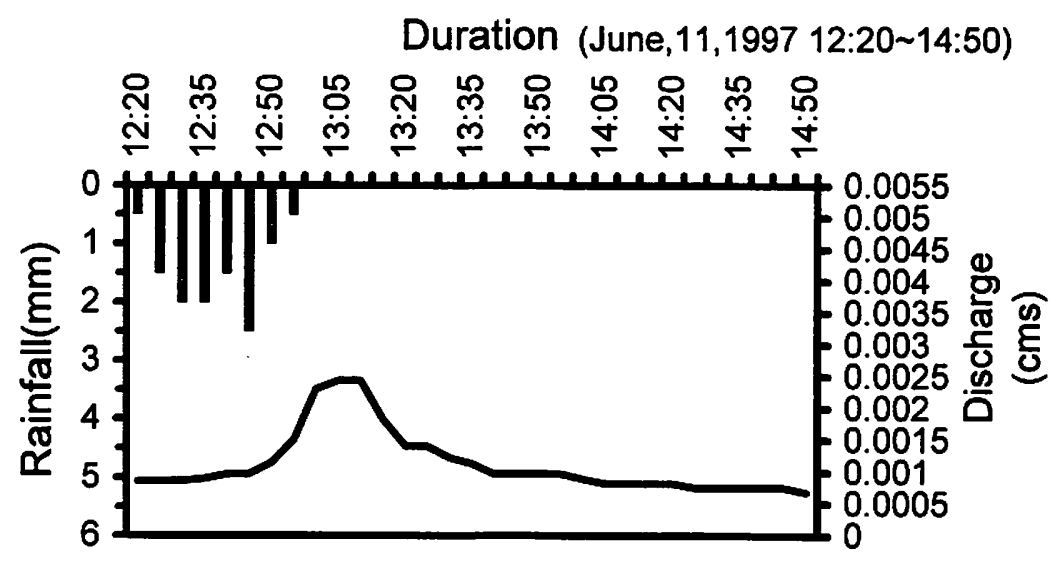

Fig. 6 Hydrograph for watershed of betel nut orchard was on the June 11,1997.

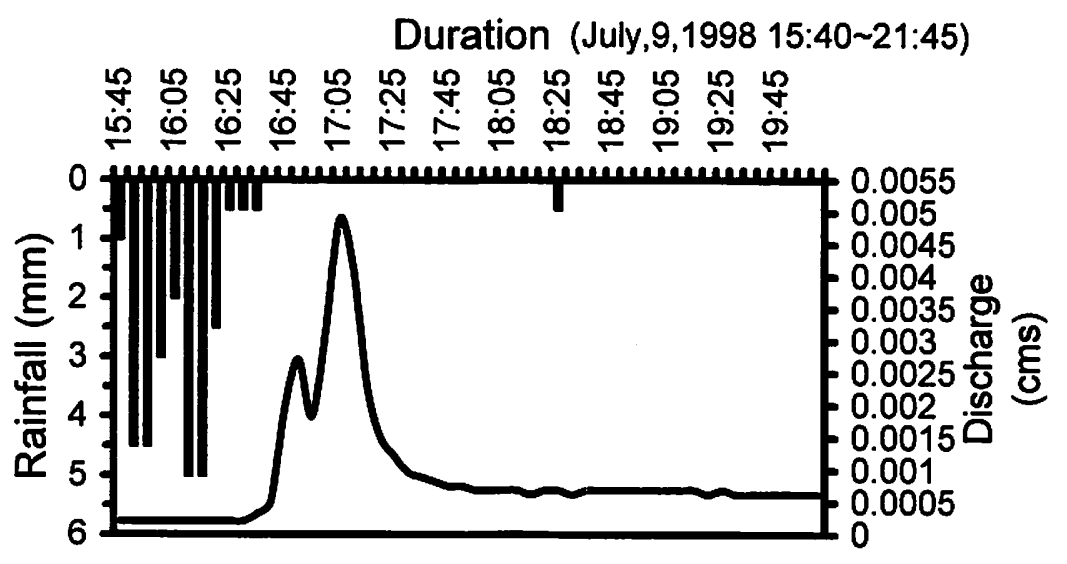

Fig.7 Hydrograph for watershed of betel nut orchard was on the July 9,1998.

\section{Acknowledgement}

We would like to thank Dr. Wu Chia-Chun for his assistance in plot of installation and observation. We also acknowledge W. C. Lin, Y. S. Huang and S. S. Huang for collecting and processing hydrological data.

\section{Reference}

Chen H. H., 1983: Forestry Hydrology. National translation Bureau press, R.O.C., 523pp.

Chen H. H., 1999: The influence of planting betel nut on hydrological environment. Journal of Chinese Soil and Water Conservation. 30(4):247-251 (in Chinese with English abstract).

Huang W. T., Pan T. J. and Chung J. D., 1991: An economic analysis of the betel nut industry in Taiwan. Bulletin of National Pingtung Institute of Agriculture. 32:213-229 (in Chinese with English abstract).

Hsu S. H., Wu C. C. and Huang G. J., 1998: To install a watershed in betel nut orchard and observation of hydrology (2), Technical report to the Council of Agriculture, R.O.C., 19pp.

Liang S., 1996: Evaluation of water retention of metropolitan slopeland watershed from recession curve parameters. Journal of Chinese Soil and Water Conservation. 27(4):293-309 (in Chinese with English abstract).

Lin J. P., 2002: Study on betel nut plantation on slopeland watershed affected the properties in middle Taiwan. Doctor Dissertation, Dep. Soil and Water Cons. National Chung Hsing University, Taichung, Taiwan (in Chinese with English abstract).

Wu H. L., Chang W. J. and Huang C. T., 1995: Preliminary results of runoff and soil erosion from slope plots of betel nut. Journal of Chinese Soil and Water Conservation. 26(3):197-209 (in Chinese with English abstract).

Wu H. L., 1998. A study on betel nut plantation on slopeland as related to soil and water conservation. Doctor Dissertation, Dep. Soil and Water Cons. National Chung Hsing University, Taichung, Taiwan (in Chinese with English abstract). 